\title{
ANALISIS SISTEM DAN PROSEDUR REKRUTMEN CALON SUMBER DAYA MANUSIA PT HERO SUPERMARKET, TBK JAKARTA
}

\author{
Oey Hannes Widjaya dan Louis Utama \\ Fakultas Ekomomi Universitas Tarumanagara \\ Email:hannesw@fe.untar.ac.id
}

\begin{abstract}
This study was conducted to determine Systems and Procedures Recruitment Candidates HR conducted at PT Hero Supermarket, to find weaknesses in systems and procedures Recruitment conducted at PT Hero Supermarket, to know the systems and procedures Recruitment Candidates human resources for this cause problems for the company to look for a proper solution in the Systems and Procedures Recruitment conducted at PT Hero Supermarket. The object of this research study is PT Hero Supermarket Tbk. engaged in the supermarket industry retailers (supermarket) which was established in 1971 and is located on Jalan Gatot Subroto Kav 64177 A South Jakarta, Indonesia. Subject Research and Systems Analysis Candidate Recruitment Procedures HR. Methods of data collection by interview and observation. Data processing techniques using the editing, coding, tabulation and komputerasisasi. The analysis and discussion of the results obtained by computerized namely Flowchart Flowchart Candidate Filing HR Recruitment, HR Candidate Recruitment Planning Flowchart, Flowchart Ad Candidate Recruitment HR, Cover Letters Candidate Selection Flowchart human resources PT Hero Supermarket Tbk
\end{abstract}

Keywords: Recruitment procedures, systems analysis, human resources

Abstrak: Penelitian ini dilakukan untuk mengetahui Sistem dan Prosedur Rekrutmen Calon Sumber Daya Manusia yang dilaksanakan pada PT Hero Supermarket, untuk mengetahui kelemahan-kelemahan dalam Sistem dan Prosedur Rekrutmen yang dilaksanakan pada PT Hero Supermarket, untuk mengetahui Sistem dan Prosedur Rekrutmen Calon Sumber Daya Manusia yang selama ini menimbulkan masalah bagi perusahaan untuk dicarikan solusi yang tepat dalam Sistem dan Prosedur Rekrutmen yang dilaksanakan pada PT Hero Supermarket. Objek penelitian penelitian ini adalah PT Hero Supermarket, Tbk. yang bergerak di bidang industri retailer pasar swalayan (supermarket) yang berdiri pada tahun 1971 dan berlokasi di Jalan Gatot Subroto Kav 64 No.177 A Jakarta Selatan, Indonesia. Subjek penelitian Analisis Sistem dan Prosedur Rekrutmen Calon Sumber Daya Manusia. Metode pengumpulan data dilakukan dengan wawancara dan observasi. Teknik pengolahan datanya menggunakan penyuntingan, pengkodean, tabulasi dan komputerasisasi. hasil analisis dan pembahasan diperoleh hasil Flowchart secara komputerisasi yaitu Flowchart Pengajuan Rekrutmen Calon Sumber Daya Manusia, Flowchart Perencanaan Rekrutmen Calon Sumber Daya Manusia, Flowchart Pemasangan Iklan Rekrutmen Calon Sumber Daya Manusia, Flowchart Seleksi Surat Lamaran Calon Sumber Daya Manusia PT Hero Supermarket, Tbk

Kata Kunci: Prosedur Rekrutmen, analisis system, sumber daya manusia 


\section{PENDAHULUAN}

Perusahaan didirikan untuk tujuan memperoleh laba supaya dapat melakukan kegiatan usahanya dalam waktu yang tidak terbatas. Konsep yang menyatakan bahwa perusahaan diasumsikan melakukan kegiatan usahanya dalam waktu yang tidak terbatas dinamakan going concern concept. Untuk menerapkan konsep ini, maka manajemen harus dapat mengendalikan dan mengukur, apakah kegiatan perusahaan tersebut sesuai dengan tujuan perusahaan. Selain itu perusahaan juga harus dapat mengikuti perubahan dan perkembangan yang terjadi dalam dunia usaha.

Salah satu tujuan perusahaan adalah merekrut sumber daya manusia atau disingkat SDM yang cocok dengan tuntutan perusahaan yaitu "the right man in the right place". Seiring dengan perkembangan dunia usaha tersebut akibat adanya teknologi yang semakin maju, perusahaan juga perlu melengkapi kegiatan-kegiatannya dengan Sistem dan Prosedur. Sistem dan Prosedur ini perlu dievaluasi dari waktu ke waktu agar supaya kegiatan perusahaan yang ada selalu up to date dengan kemajuan teknologi komputer. Komputer sebagai alat bantu dalam mengelola data-data flowchart. Flowchart merupakan alat bantu juga dalam menganalisis Sistem dan prosedur apakah sudah berjalan sesuai dengan tujuannya.

Ada bermacam-macam kegiatan yang mempengaruhi perusahaan dalam mencapai tujuannya, seperti: kegiatan SDM, Keuangan, Operasional, Pemasaran dan lain-lainnya. Karena banyaknya kegiatan-kegiatan perusahaan, maka penelitian ini akan dibatasi topik yang menyangkut pembahasan kegiatan mengenai Sistem dan Prosedur Rekrutmen Calon SDM.

Perusahaan melakukan aktivitas Rekrutmen SDM, karena SDM memegang peranan penting dalam kegiatan perusahaan. Tanpa SDM, perusahaan tidak bisa berbuat apa-apa. Pada PT. Hero Supermarket, Tbk. Terdapat masalah didalam SDM yaitu Rekrutmen tidak dilakukan berdasarkan Sistem dan Prosedur, sehingga sering SDM yang direkrut tidak sesuai dengan kebutuhan departemen yang memerlukannya. Rekrutmen tidak terlepas dari Sistem dan Prosedur, dimana terdapat masalah didalam Sistem dan Prosedur yang tidak pernah dievaluasi, data SDM tidak akurat dan banyak SDM yang tidak bekerja sesuai dengan keterampilannya. Beberapa permasalah yang dihadapi oleh PT Hero Supermarket, Tbk adalah: Banyak SDM yang direkrut tidak sesuai dengan The Right Man In The Right Place. Adanya keterlambatan antara Rekrutmen dengan kebutuhan yang sangat mendesak di Direktorat/Departemen yang membutuhkan calon SDM tersebut, data kebutuhan SDM dengan ketersediaan SDM tidak akurat, belum adanya Sistem dan Prosedur Rekrutmen Calon SDM yang baik bagi PT. HERO Supermarket, Tbk Rekrutmen SDM sering tidak sesuai dengan kebutuhan yang diinginkan oleh Direktorat/Departemen yang membutuhkan, dan belum adanya keamanan dan kerahasiaan dalam Sistem dan Prosedur Rekrutmen dalam SDM pada PT. Hero Supermarket, Tbk. Hal ini menarik perhatian untuk diteliti dengan tujuan agar permasalahan yang ada dapat diketahui penyebabnya sehingga dapat diberi saran permasalahannya.

Berdasarkan permasalahn diatas, maka perumusan masalah penelitian ini adalah. Bagaimana Analisis Sistem dan Prosedur Rekrutmen Calon SDM Selama ini yang diterapkan oleh perusahaan sehingga menimbulkan masalah adanya penerimaan Calon SDM yang tidak sesuai dengan keinginan pemakai sehingga data menjadi tidak akurat? Bagaimana Analisis Sistem dan Prosedur Rekrutmen Calon SDM Disusun sehingga dapat 
menghilangkan masalah dalam penerimaan Calon SDM yang sesuai dengan keinginan pemakai data menjadi akurat?

\section{KAJIAN TEORI}

Menurut Schuler dan Jackson (1997: 227), "Rekrutmen antara lain meliputi upaya pencarian sejumlah calon SDM yang memenuhi syarat dalam jumlah tertentu sehingga dari mereka perusahaan dapat menyeleksi orang-orang yang paling tepat untuk mengisi lowongan pekerjaan yang ada." Menurut Sjafiri Mangkuprawira (2003:57), "Rekrutmen adalah proses pencarian atau mengundang calon-calon SDM yang mempunyai kemampuan sesuai dengan rencana dan kebutuhan organisasi di waktu tertentu, untuk melamar kerja." Sondang P. Siagian (1996: 102), berpendapat "Rekrutmen adalah proses mencari, menemukan dan menarik para pelamar yang kapabel untuk dipekerjakan dalam dan oleh suatu organisasi."

Menurut Randall S.Schuler (1997), Tujuan Rekrutmen SDM bagi perusahaan sangatlah penting. SDM menentukan produktivitas perusahaan dan pada akhirnya akan mempengaruhi perkembangan dan kemajuan usaha. Oleh karena itu, sistem Rekrutmen yang ditetapkan perusahaan memiliki tujuan untuk memilih SDM dengan keunggulan kompetitif yang dibutuhkan perusahaan. Tujuan umum dari proses Rekrutmen adalah menyediakan suatu pool calon SDM yang memenuhi syarat bagi perusahaan.

Menurut Hasibuan (2002:44), Metode Rekrutmen yaitu upaya memperoleh calon SDM melalui sumber internal maupun eksternal, perusahaan menggunakan berbagai cara atau metode. Job posting memperlihatkan pada semua karyawan pembukaan lowongan yang ada di sebuah perusahaan. Job posting ini dapat meningkatkan pengetahuan karyawan akan tingkat gaji, uraian tugas, promosi umum dan prosedur transfer. Job posting biasanya didapatkan dari papan pengumuman, buletin perusahaan, atau diumumkan pada rapat-rapat staf. Sebagian perusahaan memiliki informasi yang berkaitan dengan ketrampilan yang tesimpan dalam dokumen-dokumen personalia. Informasi umum antara lain mencakup nama, nomor induk karyawan, klasifikasi pekerjaan, pekerjaan sebelumnya, pengalaman, dan tingkat gaji. Daftar ketrampilan juga harus mencakup minat kerja karyawan, pilihan geografis dan tujuan karir.

Menurut Randall S.Schuler (1997:156-157), Kendala-kendala Rekrutmen yaitu: Faktor-faktor organisasional yang meliputi kebijakan promosi dari dalam, yaitu apabila terjadi kekosongan jabatan maka akan diisi oleh, karyawan yang ada di dalam, kebijakan tentang imbalan yang meliputi gaji/upah dan tunjangan-tunjangan, kebijakan tentang status kepegawaian dan rencana SDM. Dalam merumuskan kebijakan perusahaan tentang system imbalan maka ada empat hal yang perlu dipertimbangkan yaitu :Kepentingan para anggota organisasi sesuai dengan kesepakatan.Kemampuan perusahaan.Keharusan mentaati peraturan, Penyeimbangan lokasi.

Kebiasaaan pencari tenaga kerja yang harus mampu bertindak dan berpikir. Kondisi eksternal (lingkungan yang harus diperhitungkan) yang meliputi: Tingkat pengangguran. Kedudukan perusahaan pencari tenaga kerja baru atau organisasi lain yang begerak di bidang kegiatan yang sama. Langka tidaknya keahlian atau keterampilan tertentu. Proyeksi angkatan kerja pada umumnya. Peraturan perundang-undangan di bidang ketenagakerjaan. Praktik rekrutmen oleh organisasi lain. Kendala terakhir yang harus dipertimbangkan oleh pencari tenaga kerja yaitu tuntutan tugas yang kelak akan dikerjakan oleh para pekerja baru tersebut. 


\section{Model Penelitian}

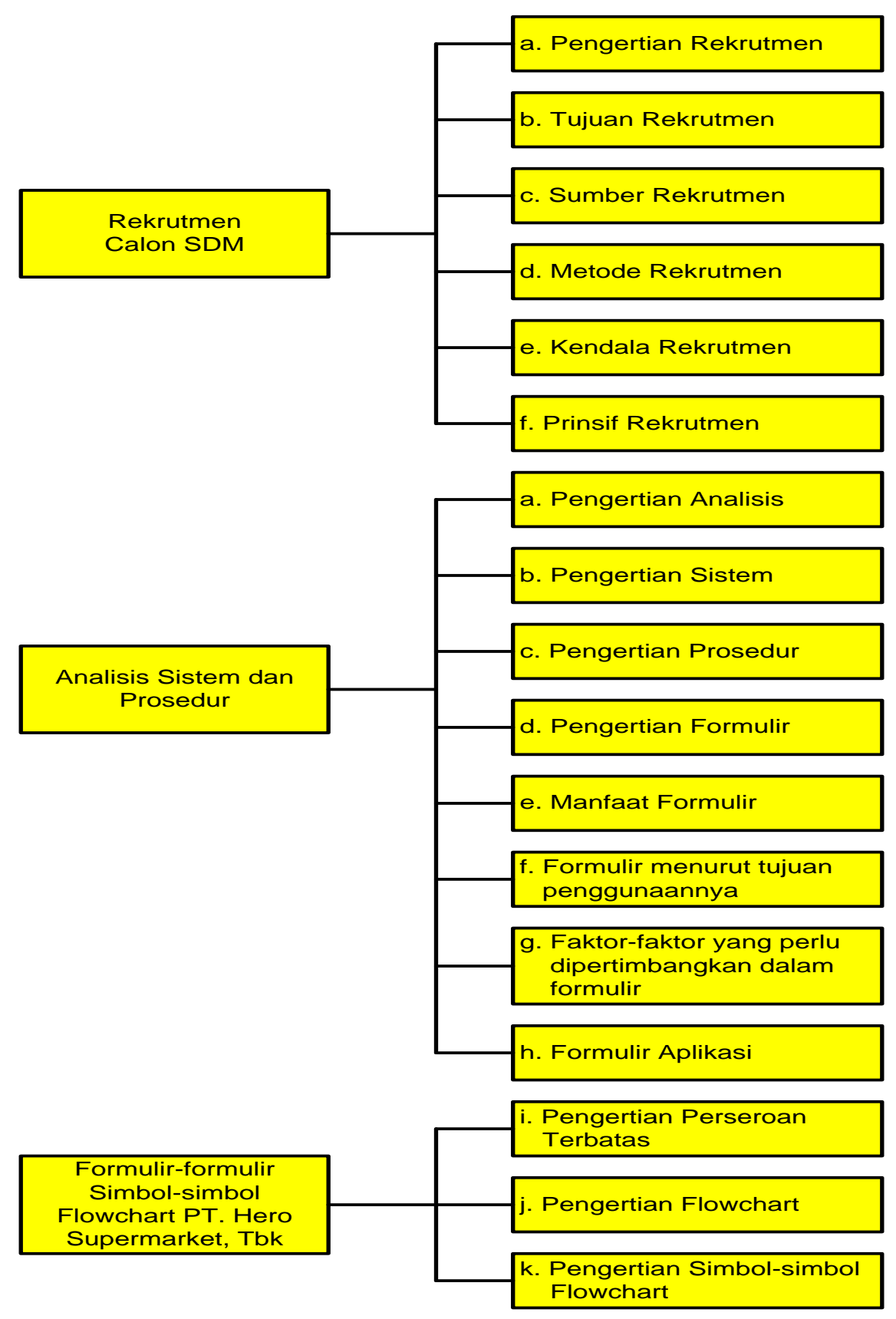

\section{METODE}

Objek penelitian penelitian ini adalah PT Hero Supermarket, Tbk. yang bergerak di bidang industri retailer pasar swalayan (supermarket) yang berdiri pada Tahun 1971 dan beralokasi di Jalan Gatot Subroto Kav 64 No.177 A Jakarta Selatan, Indonesia. Penelitian yang dilakukan adalah mengenai Analisis Sistem dan Prosedur Rekrutmen Calon Sumber Daya Manusia, karena ditemukannya masalah seperti yang dipaparkan pada identifikasi masalah 
Data-data yang telah dikumpulkan melalui teknik pengolahan data, kemudian diolah dengan menggunakan teknik pengolahan data sebagai berikut: (1) Pengkodean. Semua data yang telah dipilih, kemudian diurutkan dan disusun menjadi serangkaian data yang berkesinambungan dengan jalan memberikan kode-kode tertentu; (2) Penyuntingan. Data yang telah dikumpulkan untuk disesuaikan dan dipisahkan dengan data yang dapat digunakan untuk mendukung penelitian ini; (3) Tabulasi. Data-data tersebut kemudian disusun kedalam satu tabulasi dalam bentuk grafik proses, sehingga grafik proses tersebut dapat dibaca dengan jelas berdasarkan data yang digunakan dalam analisis untuk merancang kembali flowchart dan formulir-formulir yang dibutuhkan dalam Sistem dan Prosedur Rekrutmen Calon SDM pada PT Hero Supermarket, Tbk.; (4) Komputerasisasi. Dari hasil data penyuntingan, pengkodean dan tabulasi tersebut, kemudian dilakukan pengolahan data dengan menggunakan komputer, untuk membantu membuat data base, flowchart dan formulir - formulir yang dibutuhkan dalam menyusun Analisis Sistem dan Prosedur Rekrutmen Calon SDM untuk mengembangkan dan memperoleh fakta yang ada pada PT Hero Supermarket, Tbk.

Proses selanjutnya setelah mengolah data adalah analisis. Tujuan teknik analisis data ini adalah untuk menyederhanakan data-data sehingga mudah untuk ditafsirkan dan dikerjakan. Data ini kemudian dianalisis dengan menggunakan teknik analisis data Rekrutmen Calon SDM pada PT Hero Supermarket, Tbk yaitu sebagai berikut, anatara lain:

a. Tahap Perencanaan Analisis Sistem dan Prosedur Rekrutmen Calon SDM Pada PT. Hero Supermarket, Tbk meliputi: (i) Mempelajari Masalah; (ii) Mengidentifikasi Masalah; (iii) MenentukanTujuan Analisis Sistem dan Prosedur; (iv) Mengidentifikasi Kendala-Kendala Analisis Sistem dan Prosedur; (v) Membuat Studi Kelayakan; (vi) Mempersiapkan Usulan Penelitian Analisis Sistem dan Prosedur; (vii)Menyakinkan Pada Manajemen tentang usulan penelitian; (viii) Menetapkan Mekanisme Pengendalian.

b. Tahap Perancangan Analisis Sistem dan Prosedur Rekrutmen Calon SDM Pada PT. Hero Supermarket, Tbk Meliputi: (i) Pemberitahuan kepada Manajemen dimulai Analisis Sistem dan Prosedur; (ii) Mengkoordinasikan Tim Kerja; (iii) Mengidentifikasikan kebutuhan Analisis Sistem dan Prosedur; (iv) Mendefenisikan kriteria kinerja Analisis Sistem dan Prosedur; (v) Mengajukan usulan pada manajemen tentang rancangan sistem dan prosedur; (vi) Menerima atau menolak perancangan Sistem dan Prosedur.

c. Tahap Analisis Sistem dan Prosedur Rekrutmen Calon SDM Pada PT. Hero Supermarket, Tbk meliputi: (i) Menyiapkan persiapan Analisis Sistem dan Prosedur Rekrutmen Calon SDM; (ii) Mengidentifikasi berbagai alternatif konfigurasi Analisis Sistem dan Prosedur Rekrutmen Calon SDM; (iii) Mengevaluasi berbagai alternatif konfigurasi Analisis Sistem dan Prosedur Rekrutmen Calon SDM; (iv) Memilih konfigurasi yang terbaik untuk Analisis Sistem dan Prosedur Rekrutmen Calon SDM; (v) Meminta Persetujuan Analisis Sistem dan Prosedur Rekrutmen Calon SDM

\section{HASIL DAN PEMBAHASAN}

Pertama. Tahap Perencanaan. Dalam tahap perencanaan peneliti perlu melakukan langkah-langkah sebagai berikut: (1) Mempelajari masalah. Mempelajari masalah apa yang sebenarnya terjadi dalam perusahaan, dan kemudian dilakukan penelitian lebih 
lanjut; (2) Mengidentifikasi masalah. Dengan penjelasan oleh peneliti, maka manajemen telah menyadari dan mendukung penulis untuk mengumpulkan semua orang-orang yang akan terlibat dalam penelitian ini, serta membantu mencari dan mengidentifikasikan dimana letak permasalahannya dan apa kemungkinan penyebabnya; (3) Tujuan Analisis Sistem dan Prosedur Rekrutmen Calon SDM. HRD Director harus mengembangkan suatu daftar tujuan Analisis Sistem dan Prosedur Rekrutmen Calon SDM yang harus dipenuhi oleh program Analisis Sistem dan Prosedur Rekrutmen Calon SDM itu guna memuaskan pemakainya; (4) Mengidentifikasi kendala-kendala Analisis Sistem dan Prosedur Rekrutmen Calon SDM. Perlu disadari Analisis Sistem dan Prosedur Rekrutmen Calon SDM tidak akan berjalan bebas dari kendala-kendala. Beberapa kendala ditimbulkan oleh lingkungan seperti laporan SDM yang diperkerjakan oleh perusahaan; (5) Membuat Studi Kelayakan. Setelah peneliti mempelajari masalah, mengidentifikasi masalah, menentukan tujuan Analisis Sistem dan Prosedur Rekrutmen Calon SDM langkah berikutnya peneliti membuat Studi Kelayakan. Studi kelayakan adalah suatu tinjauan sekilas pada faktorfaktor utama yang akan mempengaruhi kemampuan Analisis Sistem dan Prosedur Rekrutmen Calon SDM untuk mencapai tujuan yang diinginkan; (6) Mempersiapkan usulan penelitian Analisis Sistem dan Prosedur Rekrutmen Calon SDM; (7) Setelah diadakan studi kelayakan, ternyata Analisis Sistem dan Prosedur Rekrutmen Calon SDM dengan memfokuskan masalah utama pada PT Hero Supermarket, Tbk. Ini tampaknya lanyak untuk dijadikan lebih lanjut, maka diperlukan penelitian Analisis Sistem dan Prosedur Rekrutmen Calon SDM. Dengan objeknya secara menyeluruh. Peneliti kemudian menyiapkan usulan penelitian Analisis Sistem dan Prosedur Rekrutmen Calon SDM yang memberikan dasar bagi HRD Director untuk menentukan perlunya dilakukan Penelitian tentang Analisis Sistem dan Prosedur Rekrutmen Calon SDM pada perusahaan. (8) Menetapkan mekanisme. Sebelum tahap Analisis Sistem dan Prosedur Rekrutmen Calon SDM dimulai, peneliti menetapkan pengendalian Analisis Sistem dan Prosedur Rekrutmen Calon SDM dengan menentukan apa yang harus dikerjakan, siapa yang melakukannya, siapa yang harus diminta keterangannya, dan kapan akan dilaksanakannya.

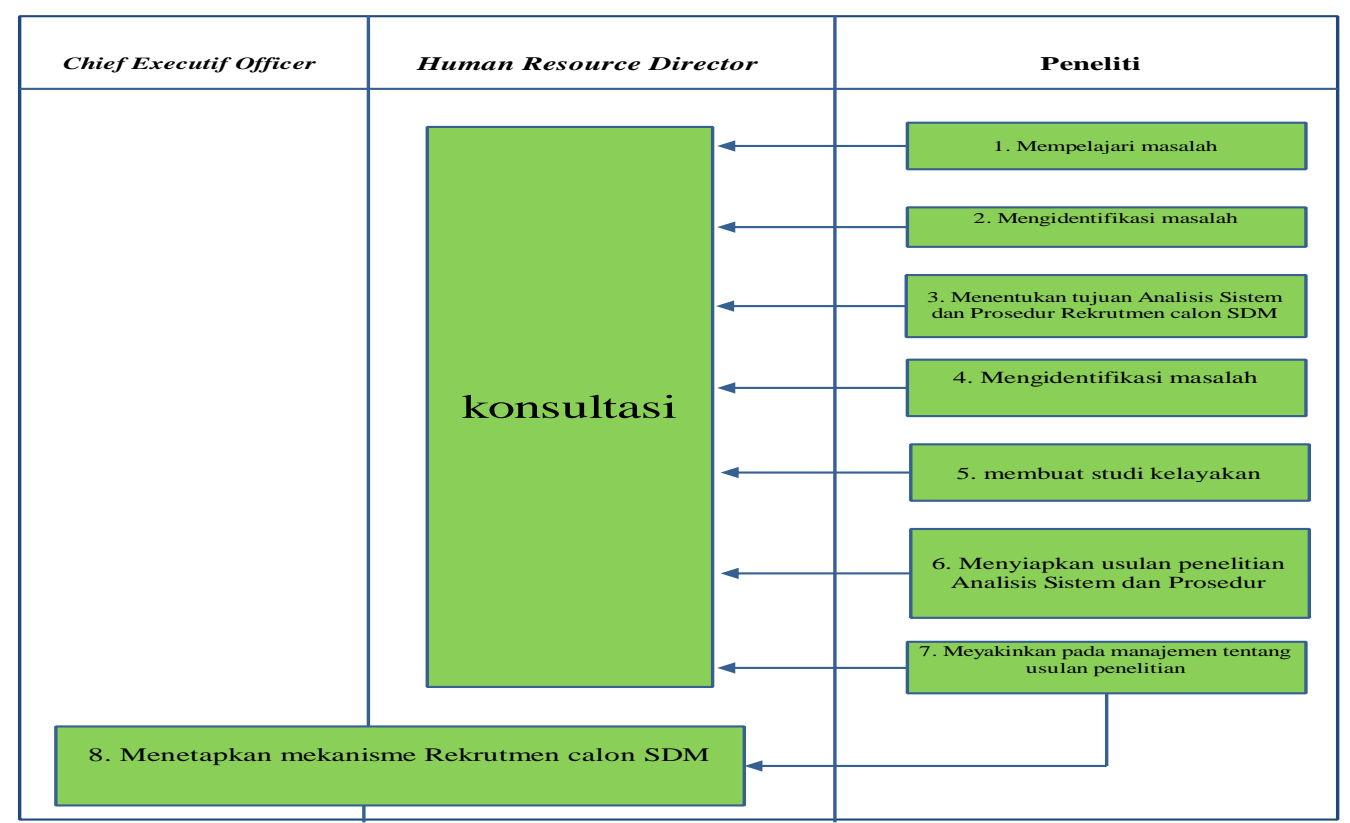

Gambar 1. Tahap Perencanaan Analisis Sistem dan Prosedur Rekrutmen Calon SDM Pada PT. Hero Supermarket, 
Tahap Perancangan Analisis Sistem dan Prosedur Rekrutmen Calon SDM pada PT Hero Supermarket, Tbk. Setelah tahap perencanaan selesai disusun dan telah mendapat persetujuan dari HRD Director, maka tahap berikutnya adalah masuk ke tahap Perancangan Analisis Sistem dan Prosedur Rekrutmen Calon SDM dengan membuat bagan tahap analisis sebagai berikut:

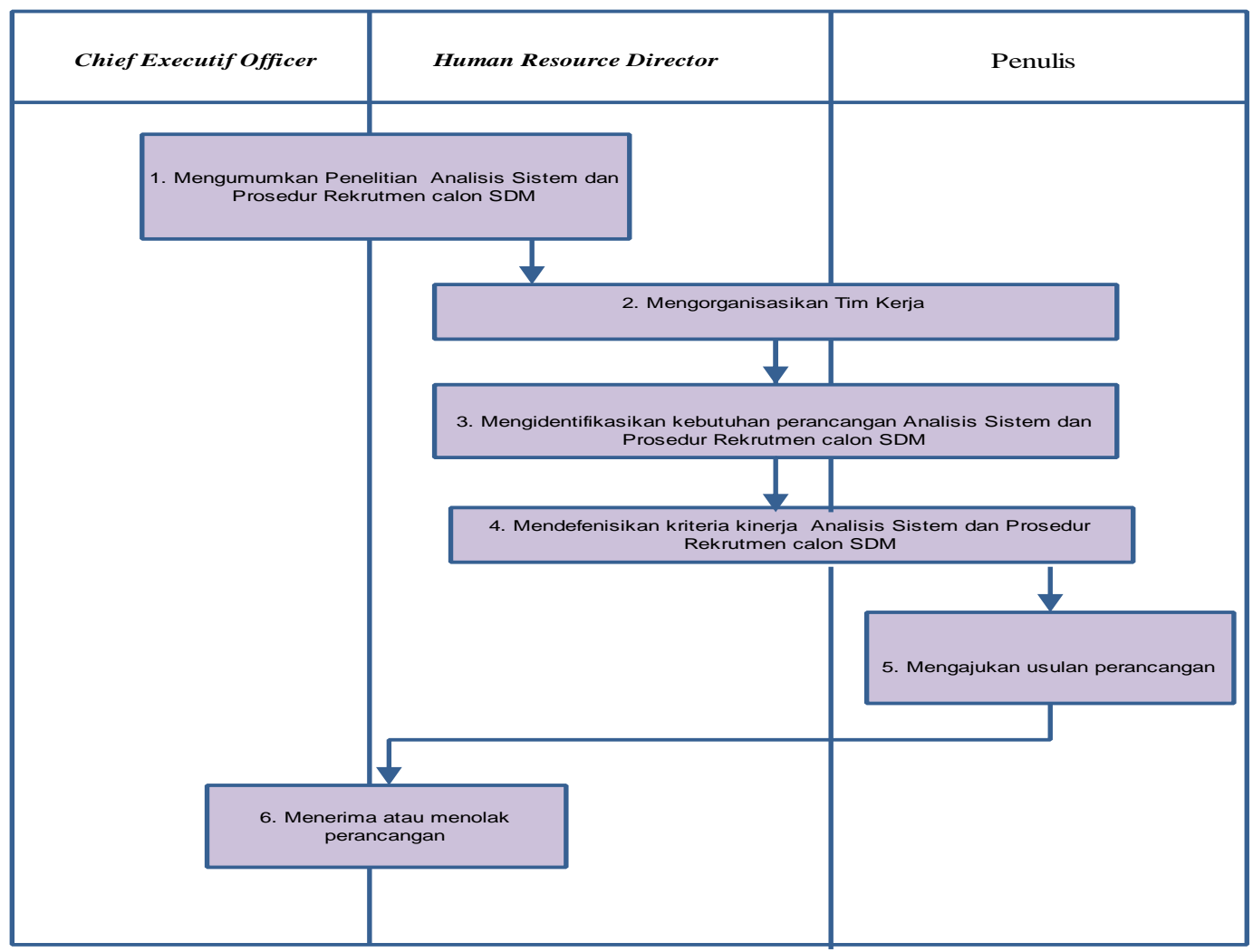

Gambar II. Tahap Perancangan Analisis Sistem dan Prosedur Rekrutmen Calon SDM Pada PT Hero Supermarket, Tbk

Pemberitahuan kepada manajemen dimulainya penelitian Analisis Sistem dan Prosedur pemberitahuan ini perlu dilakukan oleh Top Management agar para SDM yang ada kaitannya dengan Analisis Sistem dan Prosedur Rekrutmen Calon SDM mengetahui dan mau bekerja sama membantu proses Analisis Sistem dan Prosedur Rekrutmen Calon SDM. Mengorganisasikan tim kerja Tim kerja yang terlibat dalam pekerjaan ini dikumpulkan agar pekerjaan ini berhasil, mereka yang terlibat dalam tim kerja ini harus berperan aktif.

Mengidentifikasikan kebutuhan Analisis Sistem dan Prosedur. Setelah memberitahukan dan mengorganisasi, maka para pekerja yang terlibat dalam kegiatannya dapat terlibat dalam berbagai kegiatan pengumpulan informasi mengenai data-data yang dibutuhkan sehubungan dengan Analisis Sistem dan Prosedur Rekrutmen Calon SDM melalui wawancara perorangan, pengamatan, pencarian catatan dan survei.

Mendefinisikan kriteria kinerja Analisis Sistem dan Prosedur Pada tahap ini adalah mengspesifikasikan secara tepat apa yang harus dicapai oleh sistem yaitu kriteria kinerja sistem. Mengajukan usulan perancangan. Peneliti memberi kesempatan kepada HRD 
Director untuk membuat Rekomendasi. Menghentikan atau bahkan keputusan terkait dengan pelaksanaan dan penerapan dari hasil Analisis Sistem dan Prosedur Rekrutmen Calon SDM.

Tabel 3. Ikhtisar Usulan Analisis Sistem dan Prosedur Rekrutmen Calon SDM pada PT.

Hero Supermarket, Tbk

1. Ikhtisar Eksekutif

2. Pendahuluan

3. Definisi masalah

4. Tujuan dan kendala system dan prosedur

5. Kriteria kinerja

6. Berbagai alternatif sistem yang memungkinkan

7. Analisis sistem dan prosedur yang disarankan

7.1 Tugas-tugas yang harus dilaksanakan

7.2 Kebutuhan Sumber Daya Manusia

8. Dampak yang diharapkan dari Analisis Sistem dan Prosedur Rekrutmen

9. Rencana pengembangan umum (tahap perencanaan, perancangan dan analisis

10. Ikhtisar

Kedua. Menerima atau menolak perancangan. Setelah menyerahkan daftar Ikhtisar usulanAnalisis Sistem dan Prosedur Rekrutmen Calon SDM. HRD Director dapat memutuskan menerima atau menolak daftar Ikhtisar usulan perancangan Analisis Sistem dan Prosedur Rekrutmen Calon SDM tersebut. Apabila disetujui peneliti dapat melanjutkan pada tahap selanjutnya.

Tahap Analisis Sistem dan Prosedur Rekrutmen Calon SDM Pada PT. Hero Supermarket, Tbk

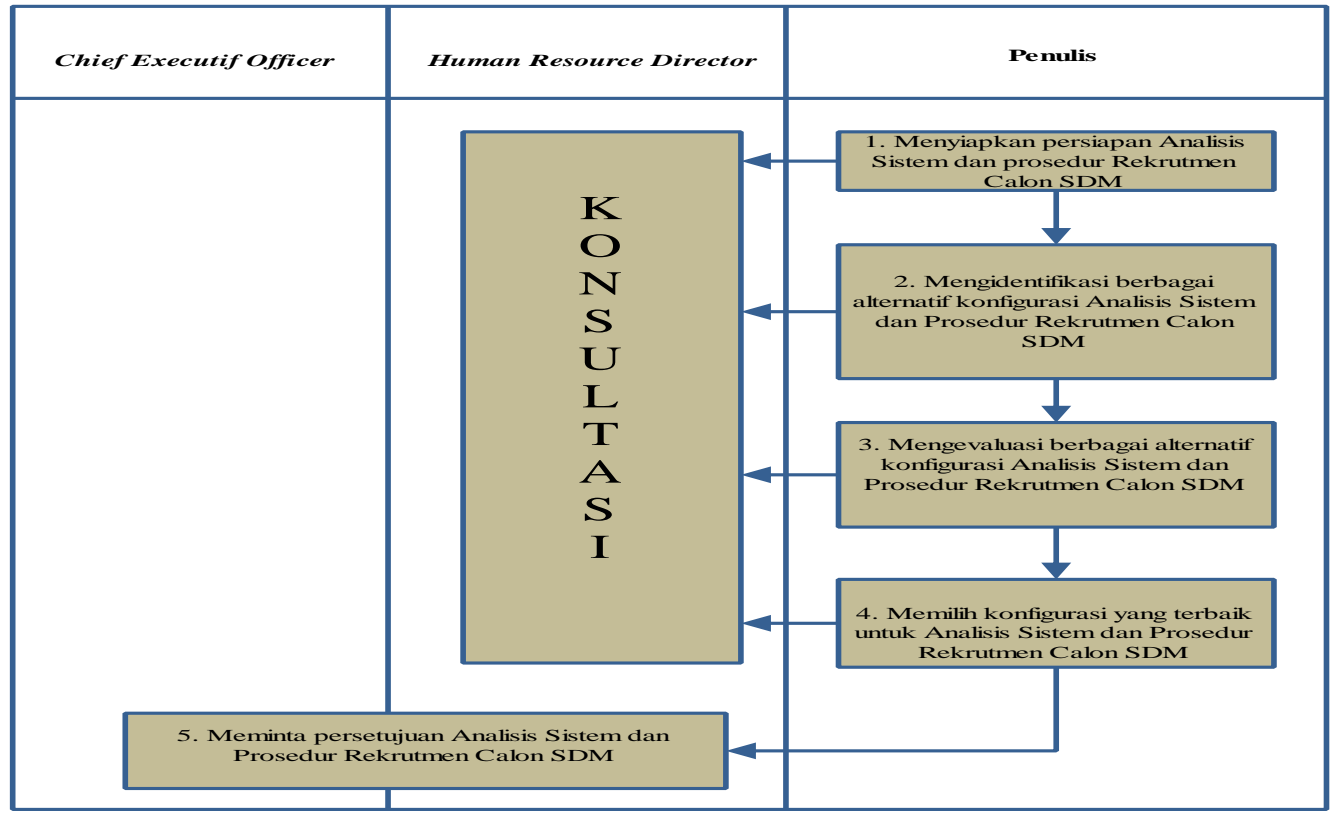

Gambar IV. Tahap Analisis Sistem dan Prosedur Rekrutmen Calon SDM Pada PT Hero Supermarket, Tbk 
Pembahasan Tahap-tahap Analisis melalui Flowchart. Tahap perencanaan: 1) Pengajuan Rekrutmen Calon SDM (FC I). Sistem dan Prosedur Pengajuan Rekrutmen Calon SDM melibatkan beberapa Departemen/Bagian Dalam perusahaan dengan tujuan agar Sistem dan Prosedur Pengajuan Rekrutmen Calon SDM berikut flowchartnya dapat membantu perusahaan merekrut Calon SDM dengan baik terkait dengan gambaran pekerjaan serta kemampuan SDM yang sesuai dengan kebutuhan perusahaan. Unit organisasi yang terlibat dalam Sistem dan Prosedur Pengajuan Rekrutmen Calon SDM yaitu: Departemen yang membutuhkan SDM dengan kemampuan standar maupun spesifik, Human Resources Director, Employment manager, Finance Director serta Finance Manager.

Formulir yang digunakan dalam Sistem dan Prosedur Pengajuan Rekrutmen Calon SDM, yaitu: (1) Formulir Dipenelitian Calon SDM (DCSDM); (2) Surat Anggaran Rekrutmen (SAR); (3) Surat Persetujuan Rekrutmen (SPR)

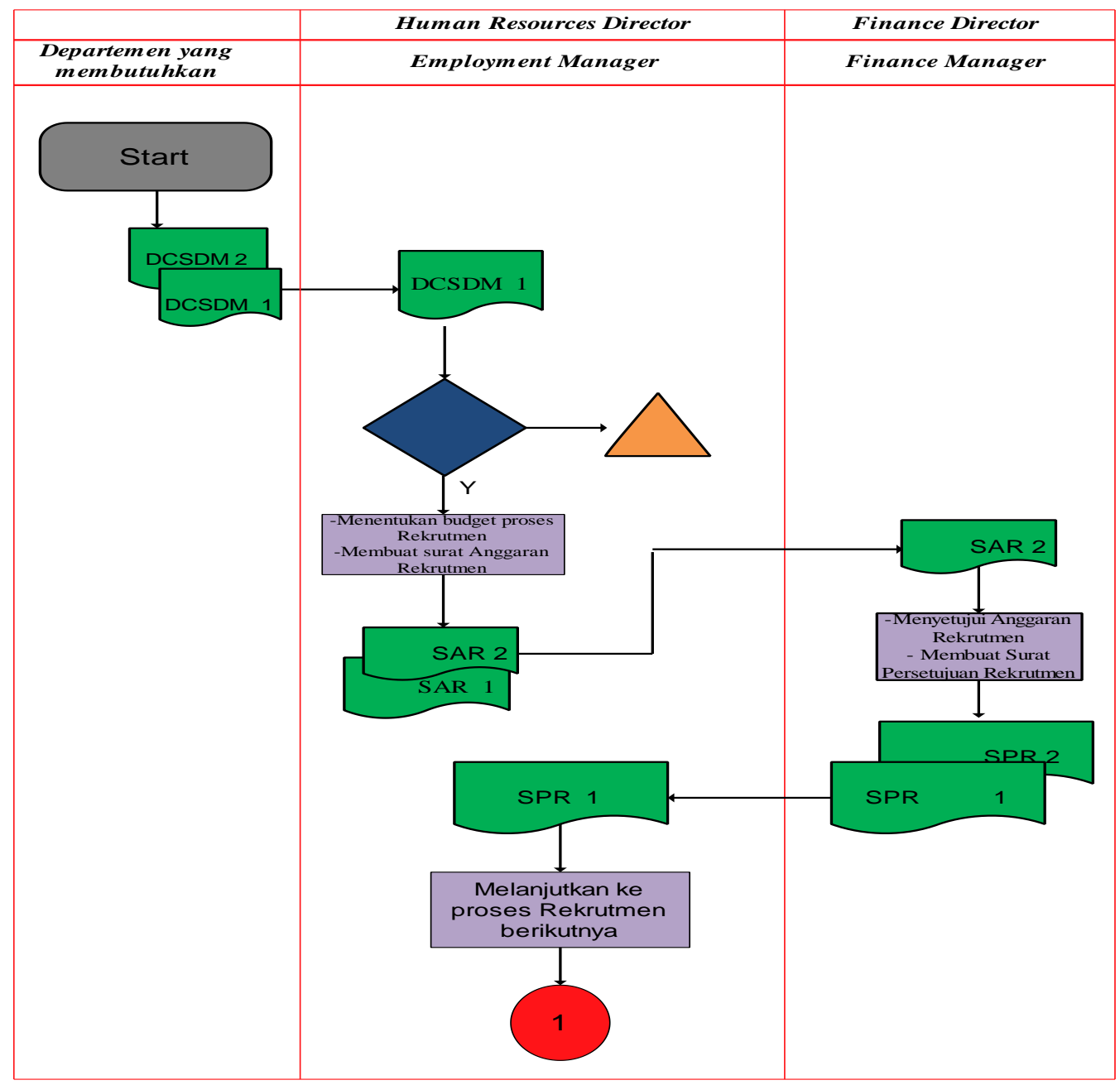

Keterangan: $\mathrm{DCSDM}=$ dipenelitian calon $\mathrm{SDM} ; \mathrm{SPR}=$ surat persetujuan rekrutmen; $\mathrm{SAR}=$ surat anggaran rekrutmen; $\mathrm{AP}=$ arsip permanent.

Gambar VI. FLOWCHART I. Unit Organisasi Yang Terlibat Dalam Sistem Dan Prosedur Rekrutmen : Pengajuan Rekrutmen Calon Sdm 
Tahap-tahap Sistem dan Prosedur Pengajuan Rekrutmen Calon SDM (FCI) antara lain, yaitu:

(1) Departemen yang membutuhkan Calon SDM mengeluarkan formulir Dipenelitian Calon SDM mengenai kriteria SDM seperti apa yang dibutuhkan sebanyak 2 rangkap yang tembusan pertama untuk Employment Manager dan kedua untuk Departemen yang membutuhkan Calon SDM.

(2) Employment Manager menerima formulir Dipenelitian Calon SDM dan menentukan kriteria-kriteria tersebut dapat diterima atau tidak, jika diterima Employment Manager menentukan budget proses Rekrutmen selanjutnya mengeluarkan Surat Anggaran Rekrutmen sebanyak 2 rangkap yang tembusan pertama untuk Finance Manager dan kedua untuk Employment Manager.

(3) Finance Manager menerima Surat Anggaran Rekrutmen dan menyetujui Surat Anggaran Rekrutmen untuk penyelenggaraan Rekrutmen selanjutnya Finance manager mengeluarkan Surat Persetujuan Rekrutmen sebanyak 2 rangkap yang tembusan pertama diserahkan ke bagian Employment Managerdan kedua untuk Finance Manager.

(4) Employment Manager Menerima Surat Persetujuan Rekrutmen dan melanjutkan ke Proses Rekrutmen berikutnya.

Perencanaan Rekrutmen Calon SDM (FC II). Sistem dan Prosedur Perencanaan Rekrutmen Calon SDM melibatkan beberapa Departemen/Bagian Dalam perusahaan dengan tujuan agar Sistem dan Prosedur Perencanaan Rekrutmen Calon SDM berikut flowchartnya dapat membantu perusahaan merekrut Calon SDM dengan baik terkait dengan gambaran pekerjaan serta kemampuan Calon SDM yang sesuai dengan kebutuhan perusahaan. Unit organisasi yang terlibat dalam Sistem dan Prosedur Perencanaan Rekrutmen Calon SDM yaitu: Departemen yang membutuhkan Calon SDM dengan kemampuan standar maupun spesifik, Human Resources Director dan Employment manager. Formulir yang digunakan dalam Sistem dan Prosedur Perencanaan Rekrutmen SDM, yaitu: (1) Surat Perencanaan Rekrutmen SDM (SPRSDM)

Tahap-tahap Sistem dan Prosedur Perencanaan Rekrutmen SDM (FC II) antara lain yaitu:

(1) Employment Manager mengeluarkan Surat Perencanaan Rekrutmen SDM (SPRSDM) sebanyak 2 rangkap yang tembusan pertama untuk Human Resources Director dan kedua untuk Employment Manager.

(2) Human Resources Director menerima Surat Perencanaan Rekrutmen SDM (SPRSDM) dan menganalisa Surat Perencanaan Rekrutmen SDM (SPRSDM) dari Employment Manager.

(3) Human Resources Director memutuskan hasil analisa Surat Perencanaan Rekrutmen SDM (SPRSDM) jika iya. Human Resources Director memberikan persetujuan pada Surat Perencanaan Rekrutmen SDM (SPRSDM) dan menyerahkan kembali Surat Perencanaan Rekrutmen SDM (SPRSDM) ke Employment Manager.

(4) Employment Manager menerima Surat Perencanaan Rekrutmen SDM (SPRSDM) dan mengeluarkan rangkap 2 Surat Perencanaan Rekrutmen SDM (SPRSDM) yg pertama sebagai bukti bahwa proses perencanaan Rekrutmen SDM dapat dilanjutkan ke proses Rekrutmen berikutnya dan kedua sebagai arsip permanen. 


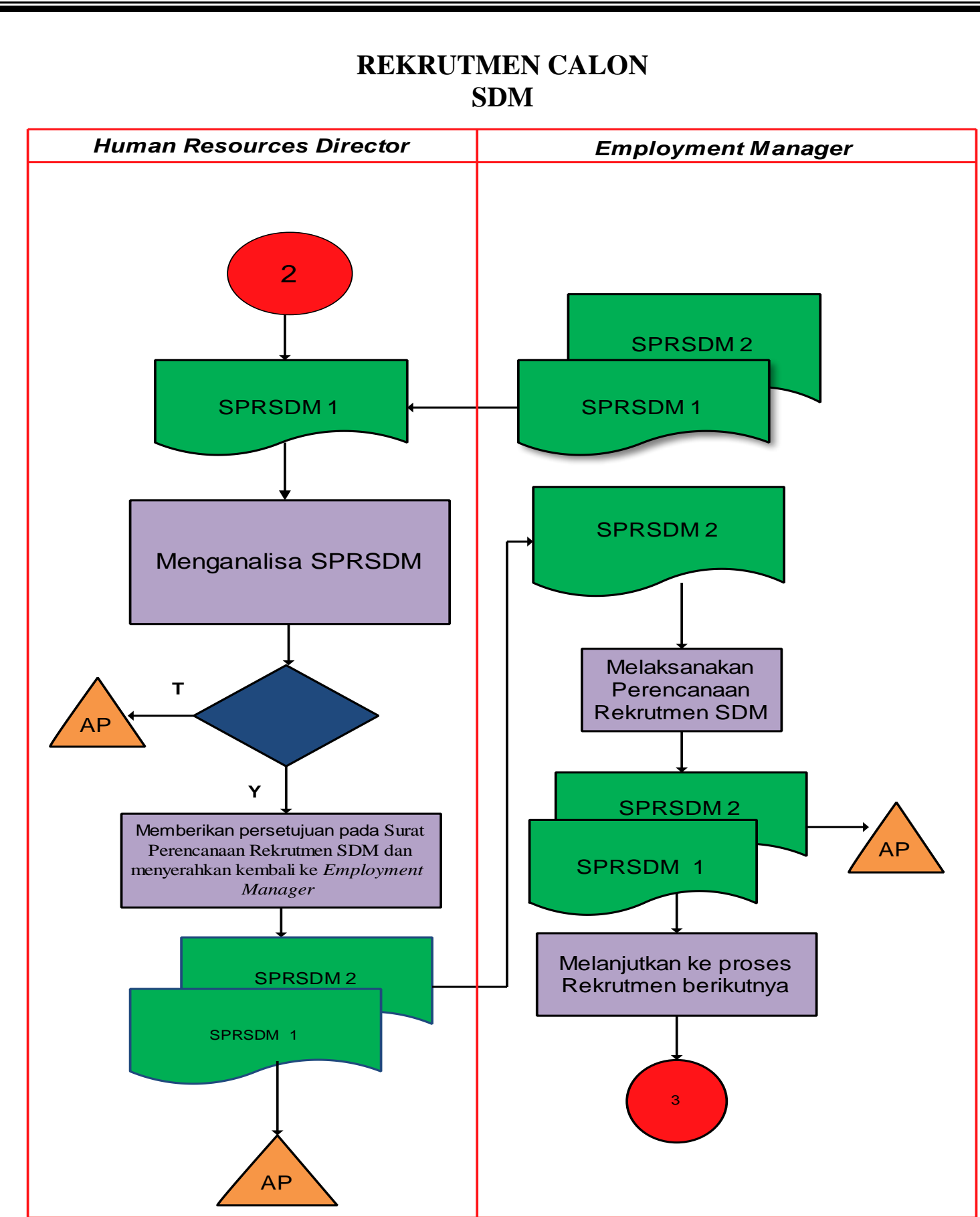

$\mathrm{SPRSDM}=$ surat perencanaan rekrutmen $\mathrm{SDM} ; \mathrm{AP}=\operatorname{arsip}$ permanen

Gambar VII. FLOWCHART II. Unit Organisasi Yang Terlibat Dalam Sistem Dan Prosedur Rekrutmen: Perencanaan

Unit organisasi yang terlibat dalam Sistem dan Prosedur: Pemasangan Iklan Rekrutmen Calon SDM (FC III). Pemasangan iklan merupakan salah satu bentuk informasi lowongan pekerjaan dan merupakan salah satu jalur Rekrutmen yang paling sering dan banyak digunakan oleh perusahaan dan instansi diberbagai media, baik elektronik maupun cetak.Unit organisasi yang terlibat dalam pemasangan iklan Rekrutmen calon SDM yaitu: Employment Manager, karena berhubungan langsung dengan proses 
Rekrutmen calon SDM perusahaan sehingga mampu mengontrol data Calon SDM yang wajib untuk didepenelitiankan atau dilengkapi.

Formulir yang digunakan dalam Sistem dan Prosedur Pemasangan Iklan Rekrutmen Calon SDM, yaitu: (1) Daftar Riwayat Hidup/Curriculum Vitae; (2) Surat Lamaran Kerja; (3) Fotocopy KTP; (4) Fotocopy Ijazah; (5) Foto

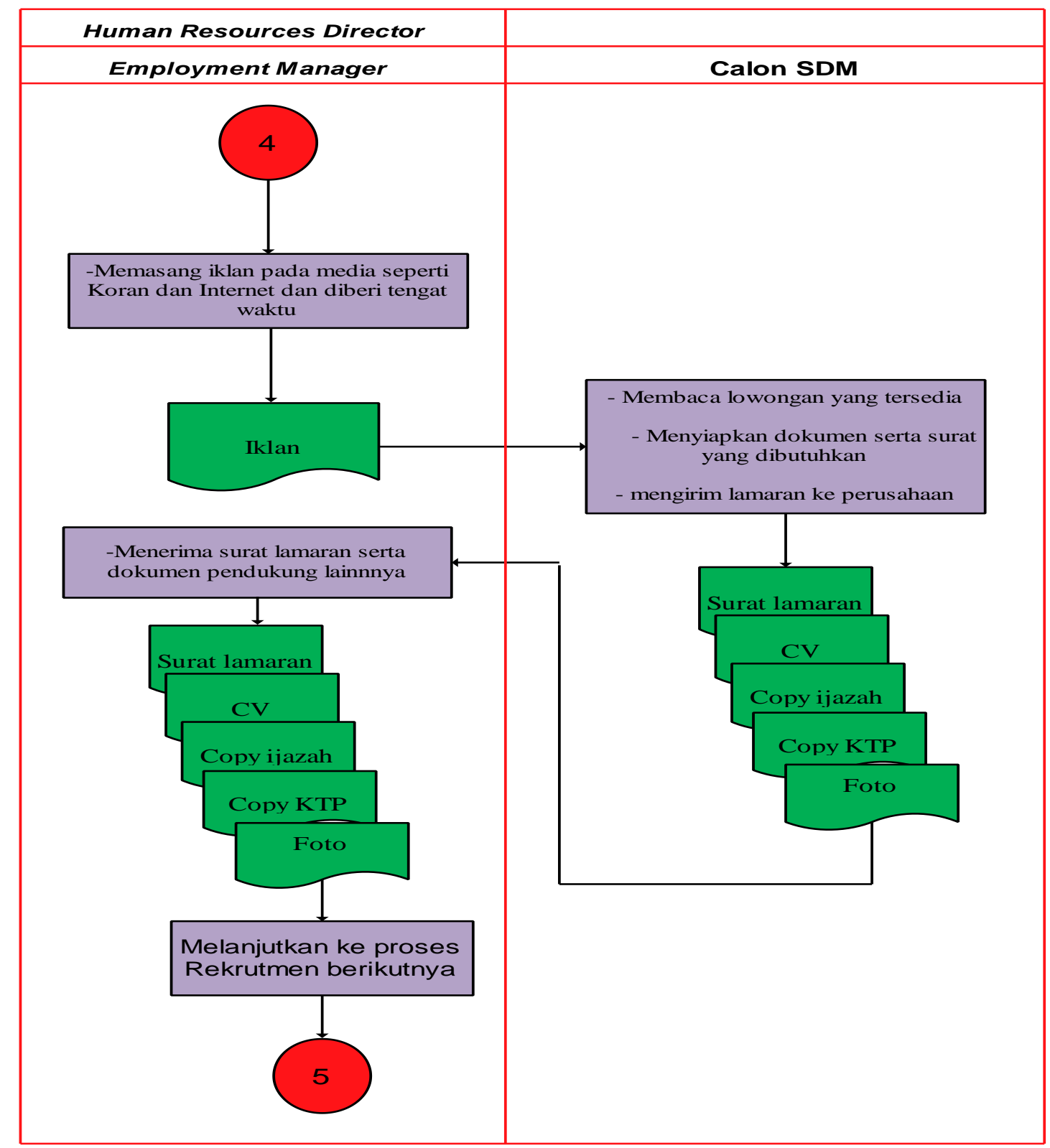

Gambar VIII. FLOWCHART III. Unit Organisasi Yang Terlibat Dalam Sistem Dan Prosedur: Pemasangan Iklan Rekrutmen Calon Sdm

Tahap-tahap Sistem dan Prosedur Pemasangan Iklan Rekrutmen calon SDM (FC III) antara lain, yaitu: (1) Employment Manager melaksanakan Rekrutmen calon SDM dengan menginformasikan lowongan melalui media seperti Koran dan internet. Dalam iklan tersebut perusahaan menjelaskan Kriteria seperti apa yang dibutuhkan dan dokumen apa 
yang perlu untuk dipenuhi.dalam iklan juga disebutkan batas periode waktu pengadaan Rekrutmen Calon SDM. (2) Calon SDM membaca lowongan yang tersedia dan menyiapkan dokumen serta surat yang dibutuhkan selanjutnya mengirimkan ke Employment Manager. (3) Employment Manager menerima surat lamaran serta dokumen pendukungan lainnya dan melanjutkan ke proses Rekrutmen berikutnya.

Unit organisasi yang terlibat dalam Sistem dan Prosedur Rekrutmen Calon SDM: Seleksi Surat Lamaran Calon SDM (FC IV). Proses seleksi berkas-berkas surat lamaran calon SDM dilakukan berdasarkan kriteria yang telah ditentukan oleh Human Resources Director dengan tujuan agar seleksi surat lamaran. Berikut flowchartnya dapat membantu perusahaan membina serta mempertanggungjawabkan calon SDM yang akan menjadi SDM bagi perusahaan. Unit organisasi yang terlibat dalam Seleksi Surat Lamaran calon SDM yaitu: Human Resources Director dan Employment Manager, karena berhubungan langsung dengan Proses Rekrutmen calon SDM perusahaan.

Formulir yang digunakan dalam Sistem dan Prosedur Seleksi Surat Lamaran Calon SDM, yaitu: (1) Surat Pengantar Seleksi (SPS); (2) Daftar Riwayat Hidup; (3) Surat Lamaran Kerja; (4) Fotocopy KTP; (5) Fotocopy Ijazah; (6) Foto 
Gambar IX. FLOWCHART IV. Unit Organisasi Yang Terlibat Dalam Sistem Dan Prosedur Rekrutmen: Seleksi Surat

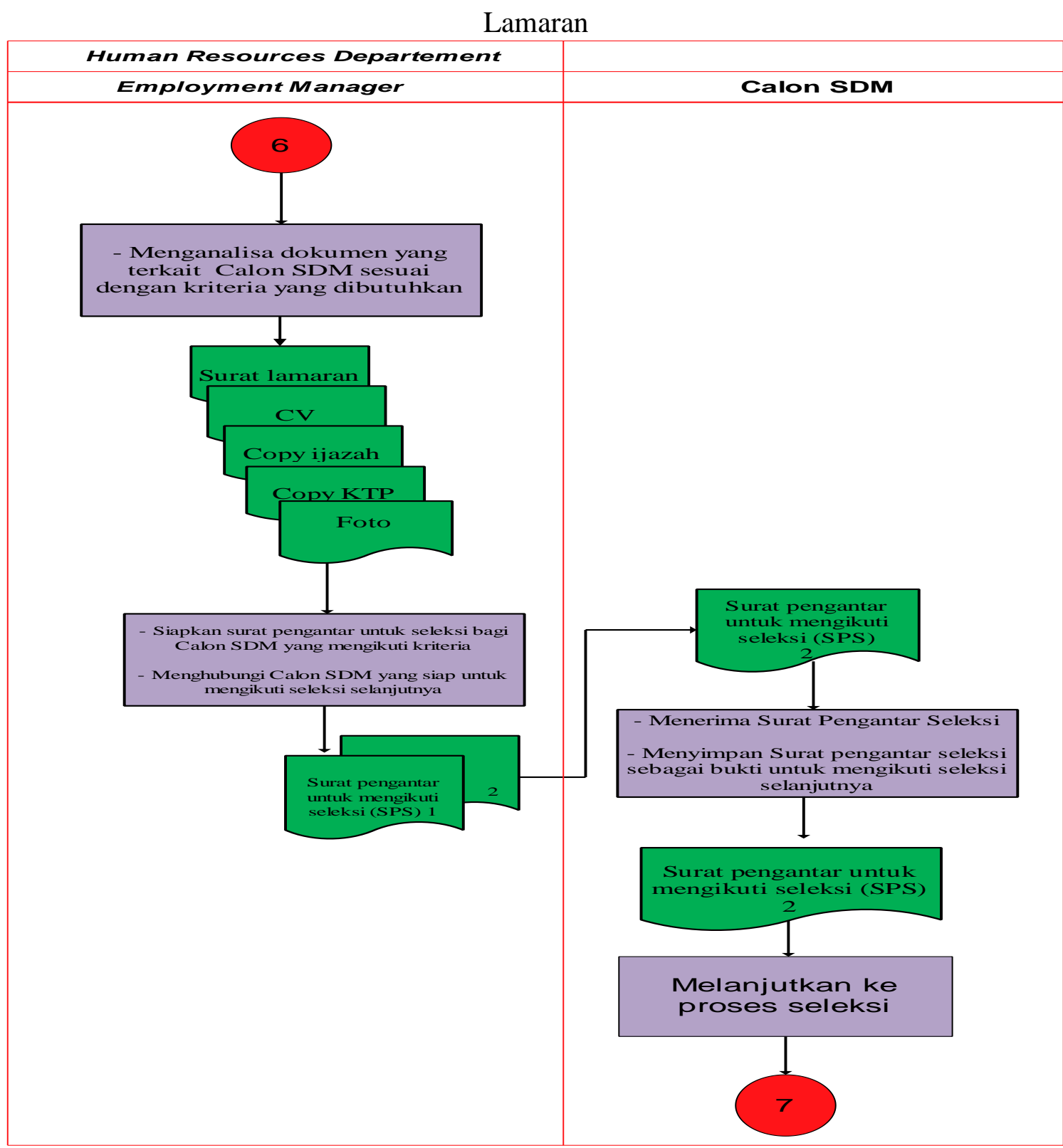

$\mathrm{CV}=$ curriculum vitae

SPS $=$ surat pengantar seleksi

Gambar IX. FLOWCHART IV. Unit Organisasi Yang Terlibat Dalam Sistem Dan Prosedur Rekrutmen: Seleksi Surat Lamaran

Tahap-tahap Sistem dan Prosedur Seleksi Surat Lamaran calon SDM (FC IV) antara lain, yaitu: (1) Employment Manager menseleksi surat lamaran dari calon SDM dan memberikan penilaian sesuai dengan kriteria yang dibutuhkan perusahaan; (2) Employment Manager mengeluarkan Surat Pengantar Seleksi (SPS) bagi calon SDM yang mengikuti kriteria. Selanjutnya Employment manager mengeluarkan SPS sebanyak 2 
rangkap yang tembusan pertama untuk Employment Manager dan kedua untuk Calon SDM; (3) Calon SDM menerima SPS dan menyimpan SPS sebagai bukti untuk mengikuti tahap seleksi selanjutnya.

\section{PENUTUP}

Simpulan. Dalam struktur organisasi PT HERO SUPERMARKET, Tbk tidak terdapat Departemen Rekrutmen dan Departemen Seleksi, Jadi selama ini Rekrutmen dan Seleksi yang menangani adalah Employment Manager. Hal ini kurang tepat karena kemungkinan untuk mendapatkan SDM yang dibutuhkan oleh User. Employment Manager bertindak hanya sendiri dalam memutuskan dan melaporkan penerimaan SDM kepada Human Resources Director.

Dalam Struktur organisasi terdapat Office Manager yang ada dibawah Human Resources Director yang tugasnya mengatur prasarana operasional, dimana yaitu yang mengatur pengiriman barang dan keberadaan kendaraan operasional. Hal ini sebetulnya bukan menjadi beban dari Human Resources Director. Dalam struktur organisasi tidak terdapat Electronic Data Processing yang mengolah data-data SDM yang terdapat pada PT HERO SUPERMARKET, Tbk.

Permasalahan Dalam Rekrutmen Calon SDM antara lain: Banyak SDM yang direkrut tidak sesuai dengan The Right Man In The Right Place. Adanya keterlambatan antara Rekrutmen dengan kebutuhan yang sangat mendesak di Direktorat/Departemen yang membutuhkan calon SDM tersebut. Data kebutuhan SDM dengan ketersediaan SDM tidak akurat. Belum adanya Sistem dan Prosedur Rekrutmen Calon SDM yang baik bagi PT HERO Supermarket, Tbk Rekrutmen SDM sering tidak sesuai dengan kebutuhan yang diinginkan oleh Direktorat/Departemen yang membutuhkan. Belum adanya keamanan dan kerahasiaan dalam Sistem dan Prosedur Rekrutmen dalam SDM pada PT Hero Supermarket, Tbk.

Jawaban atas permasalahan yang ada pada PT HERO SUPERMARKET, Tbk . Permasalahan yang ada pada PT HERO SUPERMARKET, Tbk ada 2 Bagian yaitu: Kesalahan dalam struktur organisasi Permasalahan ini merupakan ranah Strategi Manajemen PT HERO SUPERMARKET, Tbk. Peneliti tidak masuk dalam ranah Strategi Manajemen PT HERO SUPERMARKET, Tbk yang menyangkut struktur organisasi, oleh karena itu perumusan masalah yang menyangkut permasalahan dalam struktur organisasi tidak dibuat, sehingga peneliti tidak memberikan jawaban atas permasalahan struktur organisasi PT HERO SUPERMARKET, Tbk atas permasalahan tersebut diatas.

Permasalahan Rekrutmen Calon SDM yang ada pada PT HERO SUPERMARKET, Tbk. Untuk menjawab perumusan masalah tersebut pada analisis dan pembahasan peneliti telah menetapkan tahap-tahap pelaksanaan Bagaimana Tahap-tahap Analisis Sistem dan Prosedur dibuat untuk mendapatkan Sistem dan Prosedur Rekrutmen Calon SDM yang terstandarisasi. Untuk menjawab perumusan masalah tersebut pada Analisis dan Pembahaasan Peneliti telah menetapkan tahap-tahap Analisis Sistem dan Prosedut Rekrutmen Calon SDM yang terstandarisasi sebagai berikut: Tahap Perencanaan Analisis Sistem dan Prosedur Rekrutmen Calon SDM Tahap Analisis Perancangan Sistem dan Prosedur Rekrutmen Calon SDM Tahap Analisis Sistem dan Prosedur Rekrutmen Calon SDM

Dengan adanya Tahap-Tahap Analisis Perancangan Sistem dan Prosedur Rekrutmen Calon SDM maka dirancang Flowchart yang menggambarkan arus dokumen/formulir serta instruksi yang terstandarisasi dalam satu Sistem dan Prosedur dari Rekrutmen Calon 
SDM. Adapun Flowchart yang dirancang meliputi : Flowchart 1: Unit Organisasi yang terlibat dalam Sistem dan Prosedur Rekrutmen : Pengajuan Rekrutmen Calon SDM. Flowchart 2: Unit Organisasi yang terlibat dalam Sistem dan Prosedur Rekrutmen : Perencanaan Rekrutmen Calon SDM. Flowchart 3: Unit Organisasi yang terlibat dalam Sistem dan Prosedur Rekrutmen : pemasangan iklan Rekrutmen calon SDM. Flowchart 4: Unit Organisasi yang terlibat dalam Sistem dan Prosedur Rekrutmen : Seleksi Surat Lamaran calon SDM.

Dengan ditetapkan Rancangan Flowchart diatas, maka Analisis Sistem dan Prosedur Rekrutmen Calon SDM dapat memenuhi keinginan pengguna SDM tepat waktu dan akurat, The Right Man In The Right Place sesuai dengan standar yang ditentukan.

Saran. Compentation \& Human Resources Administration disarankan digabung dengan Payroll Departemen dan berada dibawah Human Resources Director. Dengan penggabungan ini diharapkan tidak terjadi birokrasi yang panjang dalam pembayaran kompensasi dan gaji para SDM pada PT. HERO SUPERMARKET, Tbk.

Office Manager yang saat ini berada dibawah Human Resources Director dipindahkan dibawah General Affairs Director. Electronic Data Processing (EDP) yang ada pada saat ini belum ada untuk membantu Human Resources Director dalam pengolahan Data-Data SDM sebaiknya dibentuk dan merupakan staff dari Human Resources Director untuk membantu mengolah data-data SDM yang bekerja di PT. HERO SUPERMARKET, Tbk

PT HERO SUPERMARKET, Tbk perlu membuat Sistem dan Prosedur Keamanan untuk melindungi / menjaga kemungkinan kecurian data SDM yang ada dalam Analisis Sistem dan Prosedur Rekrutmen calon SDM (Dengan Gambar X yang Peneliti sarankan kepada Manajemen PT. HERO SUPERMARKET, Tbk )

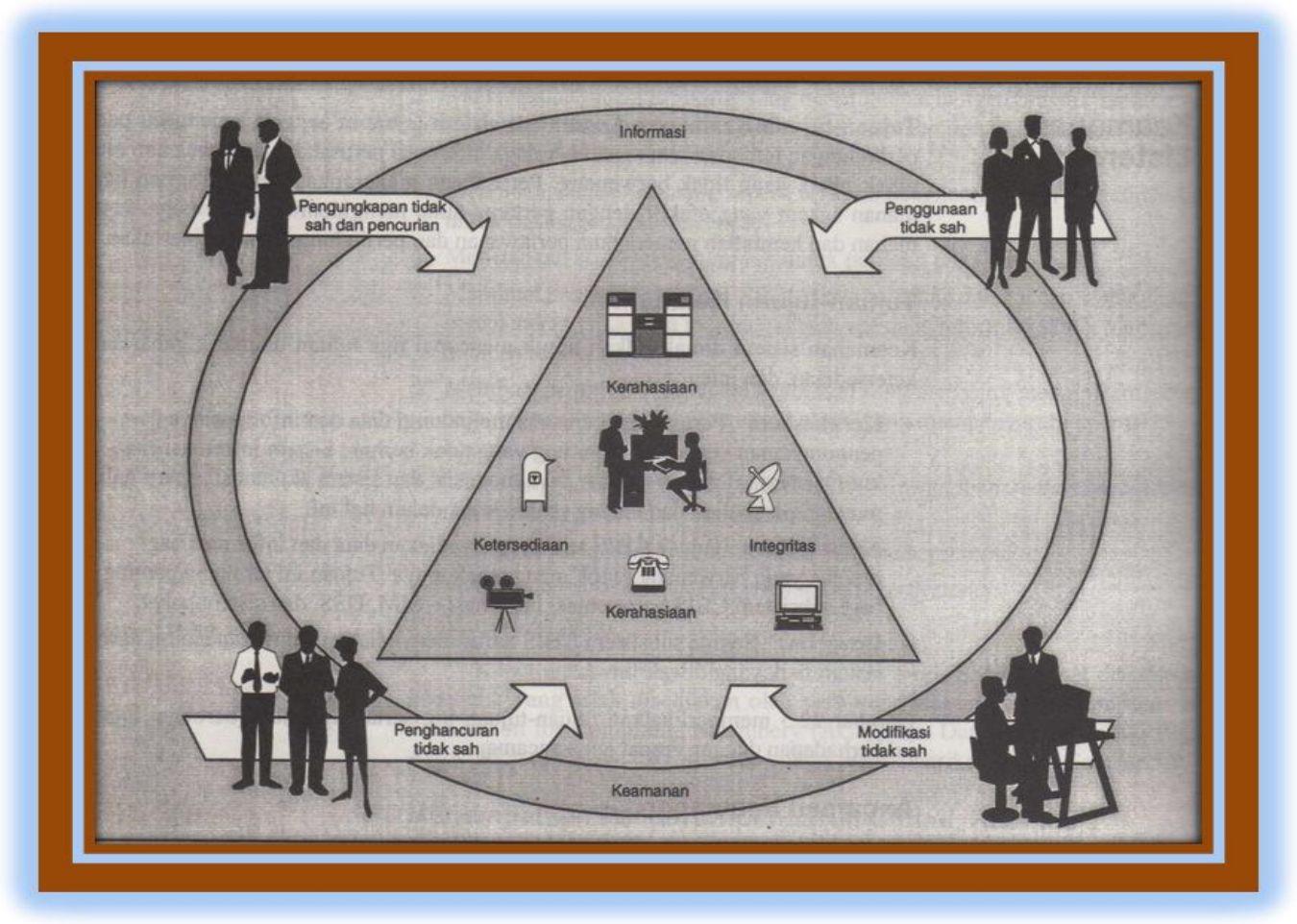

Gambar X. Saran Keamanan Dan Kerahasiaan Data Sdm 


\section{DAFTAR RUJUKAN}

Dessler, Gary (1997) Manajemen Sumber Daya Manusia, Jilid I, Edisi Bahasa Indonesia. Jakarta: PT Prehallindo

Flippo, Edwin B. (1984) Manajemen Personalia (Terjemahan Moh. Masud), Jilid I, Edisi Ke-6. Jakarta: Erlangga

Grifin, Ricky W., and Ebert, Ronald J (1998) Bisnis, Jilid I, Edisi Bahasa Indonesia. Jakarta: PT. Prenhallindo

H. M. Jogiyanto (2000). Sistem Informasi Akuntansi Berbasis Komputer, Edisi Kedua, Yogyakarta: BPFE

Hasibuan, Malayu S.P. (2003) Manajemen Sumber Daya Manusia. Jakarta: Haji Masagung

Henki Idris Issakh (2000) Teori Bisnis untuk Perusahaan Modern. Jakarta: Yayasan Rivo

Umar Husein (1997) Riset Sumber Daya Manusia Dalam Organisasi. Jakarta: Penerbit PT. Gramedia Pustaka Utama

Marimin, et.al. (2006) Sistem Informasi Manajemen Sumber Daya Manusia. Edisi Pertama. Jakarta: PT Gramedia Widiasarana Indonesia.

McLeod, Jr, Raymond (1995) Management Information System (Terjemahan Hendra), 6th Edition, Jilid I dan Jilid II. Prentice-Hall, Inc

Mulyadi (1989) Sistem Akuntansi, Edisi Kedua. Yogyakarta: Sekolah Tinggi Ilmu Ekonomi-YKPN

Schuler, S, Randall., and Jackson, Susan E (1997) Manajemen Sumber Daya Manusia Menghadapi Abad Ke-21, Edisi keenam. Jakarta: Erlangga

Soebagio, Atmodiwiryo (2005) Manajemen Pelatihan dan Pengembangan. Jakarta: PT Ardadizya Jaya

Veithzal Rivai (2005) Manajemen Sumber Daya Manusia untuk Perusahaan, Edisi Kedua. Jakarta: PT Rajagrafindo Persada

Zaki Baridwan (1993) Sistem Akuntansi: Penyusunan Prosedur dan Metode, Edisi Kelima. Yogyakarta: BPFE 